\title{
As interações comunicativas entre familiares ouvintes e sujeitos surdos: possibilidades de ressignificações
}

The communicative interactions between hearing family members and deaf subjects: possibilities of reframing

Las interacciones comunicativas entre familiares oyentes y sujetos sordos: posibilidades para resignificarlas

Michele Toso Cappellini

Mestra pela Universidade Federal de São Carlos, São Carlos, São Paulo, Brasil.

micheletoso2013@gmail.com

ORCID - https://orcid.org/0000-0001-8502-3196

Lara Ferreira dos Santos

Professora doutora na Universidade Federal de São Carlos, São Carlos, São Paulo, Brasil. larasantos.ufscar@gmail.com

ORCID - https://orcid.org/0000-0002-3196-9346

Recebido em 10 de agosto de 2020

Aprovado em 20 de outubro de 2020

Publicado em 25 de novembro de 2020

\section{RESUMO}

As interações comunicativas entre familiares ouvintes e sujeitos surdos é uma temática incipiente, desafiante. A família é o primeiro e mais próximo grupo social com o qual o sujeito mantém as relações, que influenciam diretamente o seu desenvolvimento global. Esta pesquisa, ancorada na abordagem histórico-cultural de Vigotski, objetivou analisar aspectos de um processo de reflexão junto a familiares ouvintes de sujeitos surdos, acerca de suas interações comunicativas em ambiente doméstico. Os participantes foram seis famílias, constituídas por membros ouvintes e um surdo, sendo este matriculado em uma escola pública inclusiva bilíngue. O percurso metodológico deu-se em três etapas: 1. Analisar as interações comunicativas no cotidiano das famílias; 2. Realizar um processo de reflexão com os familiares acerca dos resultados obtidos na etapa $1 ; 3$. Repetir a etapa 1 visando identificar contribuições da etapa 2 para as interações comunicativas. As etapas foram videogravadas e norteadas pelo instrumento "Escala de Avaliação da Linguagem Oral no Contexto Familiar (EVALOF)", adaptado para essa pesquisa. Como resultados constatamos que a forma mais frequente de comunicação na etapa 1 foi a bimodal. Comparando as características comunicativas nas etapas 1 e 3, houve melhora no desempenho de diversos itens da escala, para todas as famílias. Já a etapa 2 possibilitou, a partir da escuta aos familiares, a ressignificação da relação destes com o membro surdo e com a Libras. As instituições de Educação Bilíngue para surdos podem e devem promover ações como esta, visto que escola e família são corresponsáveis pela constituição dos surdos enquanto sujeitos bilíngues.

Palavras-chave: Surdez; Língua de Sinais; Interação familiar. 
http://dx.doi.org/10.5902/1984686X48563

\section{ABSTRACT}

The communicative interactions between hearing family members and deaf subjects is an incipient and challenging theme. The family is the first and closest social group with which the subject nurtures your relations, which affect directly in their global development. This research, rooted in Vygotski's historic-cultural approach, aimed at analyzing aspects of a reflective process along with hearing family of deaf subjects about their communicative interactions in the domestic environment. The participants were six families,constituted by hearing people and a deaf member, who was enrolled in a public school Bilingual Inclusive Education. The methodology consisted of three stages: 1. Analyzing the communicative interactions in their family routines; 2 . Performing a reflexive process, with the family members about the results obtained in stage 1; 3. Repeating stage 1 seeking to identify contributions from stage 2 for the communicative interactions. The stages were video-recorded and guided by the "Scale of Oral Language Assessment in Family Context (EVALOF)" instrument, adapted for this research. Comparing communicative characteristics in steps 1 and 3 , there was an improvement in the performance of several items of the scale for all families. Step 2 provided, from listening to family members, the resignifying of their relationship with the deaf member and LIBRAS (Brazilian Sign Language). Bilingual Education institutions for deaf can and should promote actions like this, since school and family are co-responsible for constitution of the deaf as bilingual subjects.

Keywords: Deafness; Sign Language; family interaction.

\section{RESUMEN}

Las interacciones comunicativas entre familiares oyentes y sujetos sordos es una temática incipiente,desafiadora. La familia es el primero y el más cercano grupo social con el que el sujeto mantienen relación, lo que influye directamente en su desarrollo como un todo. Esta investigación, basada en el enfoque histórico-cultural de Vigotski, se propone a analizar aspectos de un proceso de reflexión junto familiares oyentes de sujetos sordos, a cerca de sus interacciones comunicativas en el entorno doméstico. Los participantes del presente análisis se componen de seis familias, constituidas por miembros oyentes y una persona sorda, estando esta matriculada en una escuela pública inclusiva bilingüe. El recorrido metodológico etapas: 1. Analizar las interacciones comunicativas en el cotidiano de las familias; 2. Realizar un proceso de reflexión con los familiares a aprtir de los resultados obtenidos en la etapa 1; 3. Repetir la etapa 1 buscando identificar contribuciones de la etapa 2 en las interacciones comunicativas. Las etapas fueron videograbadas y guiadas por el instrumento "Escala de Evaluación del Lenguaje Oral en el Contexto Familiar (EVALOF)", adaptado para este trabajo. Como resultados, constatamos que la forma más frecuente de comunicación, en la etapa 1, fue la bimodal. Al comparar las características comunicativas en las etapas 1 y 3 , hubo mejoras en el desempeño de diversos factores de la escala, para todas las familias. En la etapa 2, se posibilitó, a partir de la escucha de los familiares, la resignificación de su relación con el miembro sordo y con la lengua brasileña de señas ("Língua Brasileira de Sinais" LIBRAS). Las instituciones de Educación Bilingües para sordos pueden y deben promover acciones como esta, ya que escuela y familia son corresponsables de la constitución de los sordos como sujetos bilingües.

Palabras clave: Sordera; Lengua de Señas; interacción familiar. 
http://dx.doi.org/10.5902/1984686X48563

\section{Introdução}

A surdez vem se destacando de forma crescente como tema de pesquisas científicas na atualidade (PINTO; SANTOS, 2020; TURETTA; LACERDA, 2020; CONCEIÇÃO; MARTINS, 2019) sendo possível identificar o enfoque na concepção de desenvolvimento do sujeito surdo - e de práticas para com estes - muito diferente das concepções clínicopatológicas, reabilitadoras e que encontram na surdez uma deficiência a ser corrigida e tratada. São estudos que consideram as relações desses sujeitos, que se constituem na e pela linguagem, tendo como fundamentação teórica a abordagem histórico-cultural, sendo Vigotski o autor considerado como um representante máximo dentre os estudiosos.

Esta abordagem fundamenta a presente pesquisa por defender que é nas relações sociais que o sujeito vai se apropriar dos modos de conduta culturais em que vive, incluindo o próprio relacionar-se e todos os seus aspectos socioculturais, linguísticos e psicoafetivos, podendo, então, singularizar-se enquanto indivíduo (VIGOTSKI, 2007).

Refletindo sobre o desenvolvimento da criança na sua relação com o outro, este abriga um papel fundamental enquanto mediador. A linguagem da criança, no seu início, desenvolve-se fundamentalmente nas relações sociais e é internalizada a partir dos processos de significação mediados por outros sujeitos, especialmente os pares mais experientes do grupo social. Em outras palavras, o desenvolvimento psicológico da criança transita por este percurso progressivo de individualização, originário das relações sociais, num contínuo transformar-se do processo interpessoal em intrapessoal. Pino (2005) também discorre sobre este percurso quando trata do desenvolvimento cultural da criança, entendendo-o como uma transposição do coletivo para o individual, isto é, uma conversão de funções sociais em funções pessoais. Segundo Vigotski (2007) é somente na e pela linguagem que os indivíduos têm condições de se desvincular de suas características tipicamente biológicas e humanizar-se, por isso, a linguagem também é considerada 0 sistema mais importante da relação social. Neste sentido, Moura (2013) afirma que o desenvolvimento pleno da linguagem só é possível se o sujeito for exposto a uma língua, compartilhada por diferentes interlocutores e utilizada em diferentes contextos. Espera-se ainda que esta exposição aconteça o mais precocemente possível, em ambientes favorecedores de linguagem e de produção de sentidos e significados.

Refletindo os espaços sociais em que o indivíduo estabelece suas relações, a família é compreendida como a unidade mais significativa das interações de um indivíduo. É o primeiro e mais próximo grupo social com o qual o indivíduo mantém as relações mais 
http://dx.doi.org/10.5902/1984686X48563

íntimas (RODRIGUERO; YAEGASHI, 2013). É dentro dela que o indivíduo vai se constituir emocional, subjetiva e socialmente (GUARINELLO; LACERDA, 2007). É nesse espaço de interações privilegiado que emergem os vínculos comunicacionais primários, constituídos de significados e sentidos, internalizados nas interações, possibilitando desenvolvimento do sujeito (KELMAN et al.,2011).

Quando tratamos de crianças ouvintes nascidas em famílias ouvintes, o convívio entre os membros, na maioria das vezes, já é suficiente para promover aquisição da linguagem pela criança. Essa mesma realidade dificilmente é encontrada nas situações em que uma criança surda surge no seio de familiares ouvintes pois, em sua maioria, utilizam da oralidade como forma de comunicação. Este fato traz prejuízos ao acesso da criança (que não ouve) às interações comunicativas $e$, por consequência, pode alterar o seu desenvolvimento linguístico de forma global (LACERDA; NASCIMENTO, 2017).

Neste sentido, Lacerda e Nascimento (2017) apontaram que, para o processo de desenvolvimento de linguagem do sujeito surdo, são fundamental o acesso e a qualidade de interação com os outros em uma língua acessível a ele. A Língua de Sinais (LS), que é uma língua visuogestual, não dependente do canal oral-auditivo, permite às pessoas surdas a aquisição e desenvolvimento da linguagem, constituindo-se assim, sujeitos linguísticos. Para este processo tornar-se uma realidade é ideal que a língua seja adquirida o mais cedo possível, de preferência em contextos comunicativos espontâneos. Sendo assim, quando a família se integra a este processo, torna-se favorecedora da constituição do sujeito, linguística e emocionalmente.

As pesquisas com familiares ouvintes de sujeitos surdos têm apontado uma mescla nos modos de se comunicar: LS, leitura orofacial, gestos, mímicas e Português Oral (OLIVEIRA et al., 2004; SILVA et al., 2007; SANTANA et al., 2008) com tendência a uma comunicação mais bimodal (GÓES, 1999; GUARINELO et al., 2013). A comunicação bimodal pode ser entendida como enunciados nas duas línguas (oral e de sinais) simultaneamente, sendo os sinais usados na ordem da gramatical língua oral e/ou o uso predominante da oralidade com a realização de alguns sinais como apoio para a língua oral.

Propor aos familiares ouvintes de crianças surdas o aprendizado da LS, a discussão acerca dos desafios comunicacionais cotidianos, a reflexão sobre a sua relação com a surdez/LS, parte da compreensão das dinâmicas dessas famílias e pode favorecer processos de ressignificação; assim, ao conduzi-las num processo de autorreflexão, 
http://dx.doi.org/10.5902/1984686X48563

vislumbra-se que este percurso seja uma oportunidade potencial de deslocamentos e transformações no modo de se comunicarem com os sujeitos surdos. (OLIVEIRA et al., 2004; SILVA et al., 2007; YUE, 2010; KELMAN et al., 2011). Estudos como estes apontam ainda como a escola, que promove formação bilíngue aos sujeitos surdos, pode e deve propiciar espaço formativos, reflexivos e de apoio aos familiares ouvintes de sujeitos surdos (LACERDA; LODI, 2010; SOUZA, 2018).

Outros trabalhos também propuseram discutir com familiares ouvintes de sujeitos surdos aspectos da surdez, da LS, da comunicação e/ou das interações comunicativas (KELMAN et al., 2011; GUARINELLO et. al., 2013) ou ao menos mobilizá-los a pensar a respeito, a partir da aplicação de roteiros de perguntas (OLIVEIRA et al., 2004; SILVA et al., 2007; SCHEMBERG et al., 2012; CARVALHO; SANTOS, 2016).

Trata-se de trabalhos que revelam o dilema das famílias entre Língua de Sinais e oralidade, em vista de favorecer o desenvolvimento linguístico de seus filhos; questão esta que, em geral, não se impõe para outras famílias. Normalmente, pais e filhos compartilham da mesma modalidade de comunicação e estes vão adquirindo e desenvolvendo a língua de modo natural, no cotidiano das relações. Já as famílias ouvintes de sujeitos surdos precisam assumir uma postura ativa de buscar meios para se comunicarem, os quais fogem do convencional. Dessa forma, além da responsabilidade de cuidar do bebê, educar e favorecer o desenvolvimento, as famílias também são convocadas a viver e conviver com essa diferença linguística, que implica“[...]adquirir uma nova modalidade de comunicação e compreender seus processos, proporcionando à criança surda uma experiência de língua necessária para seu desenvolvimento[...]" (SOUZA, 2018, p.73).

Somado a este complexo contexto, há de se considerar as dificuldades previstas no aprendizado de uma segunda língua, como bem exposto por Revuz (1998) em seu trabalho. Segundo a autora, aprender uma língua exige muito esforço, uma flexibilidade psíquica que inclui as dimensões cognitiva, corporal e subjetiva. É um deslocamento contínuo, um sair de si, um tornar-se outro. Este processo é perturbador e modifica aquilo que estava inscrito em nós com as palavras da nossa primeira língua. Também inclui a dimensão afetiva, sendo o desejo o motor propulsor do aprendizado. As famílias ouvintes de sujeitos surdos, portanto, são convocadas a lidar com toda essa demanda bastante intensa.

Ao concretizar um espaço para que familiares ouvintes de sujeitos surdos possam estar (re) unidos para refletir, discutir e aprender sobre suas interações comunicativas cotidianas, a partir de um outro mediador, faz-se oportuno o resgate dos conceitos eleitos, 
http://dx.doi.org/10.5902/1984686X48563

para esta pesquisa, da abordagem histórico-cultural. Primordialmente pelo valor dado ao processo, ao movimento e às possibilidades de transformações, bem como de desenvolvimento humano, contínuo e constante, a partir das suas relações sociais.

De igual importância, os modos de conduta culturais em que vive o sujeito, incluindo o próprio relacionar-se e todos os seus aspectos socioculturais, linguísticos e psicoafetivos podem ser modelados por formas diferentes de mediação social. A partir de um processo de mediação na e pela linguagem é possível promover processo de significação e (re) significação de fatos, ideias, objetos e funções sociais. Neste sentido, Góes (1999) ressaltou sobre a formação do indivíduo como um processo constituído nas relações sociais, envolvendo a mediação do outro, produzindo significados em relação a si próprio e ao mundo da cultura.

Cabe destacar que ainda que o significado esteja nas relações sociais, as pessoas não internalizam a relação em si, mas os significados que atribuem a elas. A linguagem é considerada o elemento mais importante para o desenvolvimento psicológico e tem como funções primordiais a comunicação, o contato social e a influência sobre os indivíduos que estão ao seu redor. Desta forma, acredita-se que o processo de mediação se forme de acordo com as demandas da comunicação, conforme aponta Lacerda (1996). Esta autora também destacou, em suas ponderações teóricas sob a perspectiva de Vigotski, o valor da característica reflexiva da linguagem, ou seja, a propriedade que a linguagem apresenta de remeter-se a si mesma. Com ela o sujeito tem possibilidade de se reconhecer, voltar-se sobre si mesmo e falar do seu próprio acontecimento.

Diante do exposto, a temática central deste trabalho se mostra bastante provocadora e carente de pesquisas, especialmente quando tratamos do tema família e surdez no âmbito da educação, como já os revelou o estudo de Souza (2018). Esse contexto mobiliza nossa escolha e o desejo de aprofundar conhecimentos sobre a relação de comunicação entre familiares ouvintes e sujeitos surdos, delineando como objetivo central deste trabalho analisar aspectos de um processo de reflexão junto a familiares ouvintes de sujeitos surdos, acerca de suas interações comunicativas em ambiente doméstico.

\section{Método}

Este estudo é um recorte da pesquisa de mestrado (CAPPELLINI, 2019) desenvolvida pela primeira autora, sob orientação da segunda autora; trata-se de um relato de pesquisa, cujo percurso metodológico está descrito nesta seção. 
http://dx.doi.org/10.5902/1984686X48563

Enraizada na abordagem histórico-cultural, esta pesquisa assume um caráter metodológico qualitativo, considerando sua dialética, seus fatores históricos e de temporalidade e, portanto, a sua não generalização. Compreendemos, assim, que a verdade é temporária e circunscrita ao cenário da pesquisa que, por sua vez, ao se articular com outros estudos, fomenta o processo investigativo (KELMAN et al., 2011).

Participaram da pesquisa seis famílias, considerando como critérios de seleção que fossem compostas por membros ouvintes e um membro surdo, sendo o sujeito surdo falante da Língua Brasileira de Sinais (Libras) e matriculado em uma instituição de ensino que desenvolve uma proposta de educação inclusiva bilíngue para surdos. Já para os familiares, o critério foi que estivessem em processo de aprendizado desta língua há pelo menos seis meses. Todas as famílias foram identificadas com nomes fictícios e os dados de sua caracterização, a seguir, foram levantados com os próprios familiares durante o processo de coleta de dados.

Família Oliva: Compõem esta família um menino surdo e seus pais ouvintes. Participam da pesquisa o filho surdo de 10 anos de idade e sua mãe. Ele está em fase de aquisição e desenvolvimento da Libras desde que foi matriculado na Escola Inclusiva Bilíngue de Educação para Surdos em 2013. Comunica-se com mais frequência pela Libras e apresenta também desenvolvimento de oralidade. Sua mãe, desde então, está envolvida com o aprendizado da Libras no curso oferecido pela escola, no entanto, mostrou-se mais assídua a partir do ano de 2017.

Família Perez: é constituída por um sujeito surdo, do sexo masculino, de 14 anos e sua avó ouvinte. Ambos participaram da pesquisa, residem juntos e estão em processo de aquisição e desenvolvimento da Libras desde 2011, quando o garoto foi matriculado na Escola Bilíngue Inclusiva de Educação para Surdos. Ele comunica-se essencialmente pela Libras e ainda apresenta déficit cognitivo decorrente da meningite. A avó é responsável legal do sujeito surdo, participa do curso de Libras oferecido pela escola com assiduidade e frequenta cursos de Libras em dois outros locais: Instituição Religiosa e Universidade.

Família Ferraz: é formada por um adolescente surdo de 14 anos e sua avó, os quais aceitaram participar da pesquisa. Residem juntos e estão em processo de aquisição e desenvolvimento da Libras desde 2011, quando garoto foi matriculado na Escola Bilíngue Inclusiva de Educação para Surdos. Ele comunica-se essencialmente pela Libras. Também neste caso a avó é responsável legal pelo sujeito surdo e participa com assiduidade do curso de Libras oferecido pela escola. 
http://dx.doi.org/10.5902/1984686X48563

Família Aquiles: é composta por uma menina surda adotiva (9 anos), sua irmã mais velha e seus pais. Participaram da pesquisa a mãe, a irmã e a criança surda. Esta se comunica com mais frequência pela Libras e também faz uso da oralidade. Iniciou a aquisição da Libras em março de 2017 quando foi matriculada na Escola Bilíngue Inclusiva de Educação para Surdos. Desde então, sua mãe e irmã têm se envolvido no aprendizado da Libras de modo sistemático no curso oferecido pela escola e, neste ano, a mãe também iniciou um curso de Libras em uma Universidade.

Família Sande: constituem esta família um garoto surdo (7 anos), sua mãe e duas irmãs menores. Foram participantes da pesquisa, a mãe e o menino surdo. Ele se comunica com mais frequência pela Libras, também faz uso da oralidade e do Implante Coclear. Sua mãe está envolvida com o aprendizado da Libras no curso oferecido pela escola, com pouca assiduidade, sendo a criança inserida na Escola Bilíngue Inclusiva de Educação para Surdos desde 2016.

Família Morete: esta família é formada por uma jovem surda de 15 anos de idade, sua mãe, padrasto e irmão menor. Participaram da pesquisa a mãe e a garota surda. Ela se comunica com mais frequência pela Libras mas também utiliza o recurso da oralidade. Está na Escola Bilíngue Inclusiva de Educação para Surdos desde 2012, quando sua mãe também iniciou o aprendizado da língua no curso oferecido pela escola, no entanto, foi pouco assídua neste processo.

Os sujeitos foram submetidos a três etapas metodológicas, norteadas pelo instrumento denominado Escala de Avaliação da Linguagem oral no contexto familiar $(\text { EVALOF })^{1}$. A escala EVALOF é um instrumento norteador que permite a observação das interações comunicativas em contexto doméstico, a partir da análise do contexto e gestão da comunicação, assim como, das funções e estratégias comunicativas utilizadas pelos familiares. Trata-se de uma ferramenta flexível que possibilita que seus itens sejam utilizados como base para processo de reflexão e assessoramento, objetivando a melhoria nas habilidades comunicativas dos membros da família e, por consequência, das habilidades linguísticas das crianças (DOMENICONI et al., 2017). Para este trabalho o instrumento foi adaptado, no sentido de adequar e acrescentar itens da escala, considerando a singularidade do contexto dos sujeitos envolvidos.

Na etapa 1 foi realizada análise das interações comunicativas de familiares ouvintes com seus membros surdos, em ambiente doméstico, registrando situações do cotidiano mais favorecedores para uso da comunicação de acordo com Domeniconi et al. (2017). 
http://dx.doi.org/10.5902/1984686X48563

Além dos contextos de comunicação selecionados, foi apresentado como complemento, no momento da realização da filmagem, um elemento externo denominado disparador, com intuito de provocar o diálogo e experiências de comunicação nem sempre rotineiras, mas que exigissem solução de problemas, acordos, novos vocábulos e construções mais elaboradas de comunicação. Este disparador foi um elemento externo trazido pela pesquisadora para que os participantes pudessem conversar a respeito.

$\mathrm{Na}$ segunda etapa ocorreu o processo de reflexão e discussão com os familiares, denominado assessoramento, a partir das observações realizadas no ambiente doméstico (etapa 1), sendo realizados quatro encontros mensais. Para as discussões elegeram-se itens da EVALOF, considerados essenciais para uma comunicação minimamente efetiva e, para os quais, a conduta dos familiares foi pouco satisfatória. Utilizaram-se perguntas e vídeos disparadores para o diálogo entre os familiares e com mediação da pesquisadora ${ }^{2}$.

$\mathrm{Na}$ etapa 3 foi realizada nova análise das interações comunicativas de familiares ouvintes com seus membros surdos, com os mesmos procedimentos executados na etapa 1 e com o propósito de identificar contribuições do processo de assessoramento para as interações comunicativas cotidianas.

Por fim, elegemos o recurso da videogravação tão relevante em pesquisas qualitativas, nos procedimentos metodológicos desenvolvidos: das interações comunicativas observadas nas etapas 1 e 3 , bem como nos quatro encontros da etapa 2 , o assessoramento. Em situações em que se faz necessária a captação de imagens em movimentos, expressões faciais e corporais, este recurso se mostra muito útil. No entanto, não se faz em substituição à presença do pesquisador no campo (GARCEZ et al., 2011, p. 260). Em nosso caso, ao considerar a Língua de Sinais como uma língua visuogestual, o registro em vídeo se mostra bastante adequado. Portanto, nossa escolha de recurso metodológico foi a de realizar as videogravações, na presença do pesquisador, associada ao diário de campo, permitindo o registro de percepções e sensações do pesquisador, a partir de sua perspectiva teórica, nem sempre captadas pelas gravações (SANTOS, 2014). Sendo a presente pesquisa cunhada na abordagem histórico-cultural, nosso olhar debruçase para a compreensão das relações e comportamento dentro de um processo e não apenas a descrição em si dos fatos (VIGOTSKI,2007).

Nos resultados e discussões são apresentadas as características comunicativas identificadas na etapa 1 , bem como os elementos discutidos na fase de assessoramento e, ainda, as mudanças observadas na última etapa. São trazidas também transcrições de 
http://dx.doi.org/10.5902/1984686X48563

trechos das videogravações, que estarão em formato de texto com letra em tamanho reduzido e itálico para diferenciação dos diálogos. Serão apresentados os nomes fictícios das famílias, compostos por: grau de parentesco (em letras maiúsculas), e sobrenome da família.

\section{Resultados e discussão}

Ao propor um processo de discussão acerca de suas interações comunicativas, os familiares ouvintes de sujeitos surdos foram inseridos num processo de autorreflexão a partir de itens da escala EVALOF, eleitos com base nas observações iniciais realizadas na primeira etapa desta pesquisa, em ambiente doméstico (LLOBERA et al., 2017).

Com a presente pesquisa desejou-se adensar a análise e a discussão de suas interações comunicativas direcionando o olhar para o tipo de relação estabelecida com a surdez, com a língua e de que forma esses fatores os constituíram enquanto sujeitos (e sujeitos em relação). Em outras palavras, nossas observações assumem a perspectiva teórica da abordagem histórico-cultural (VIGOTSKI, 2007) e, portanto, não se destinaram apenas ao modo como as famílias se comunicam, mas para o processo pelo qual essa comunicação foi construída. Não se trata de uma mera descrição das interações comunicativas, mas da investigação das relações dinâmico-causais intrínsecas ao modo de comunicar. Sob esta ótica, a fase de assessoramento pode elucidar alguns aspectos de todo esse processo e, ainda, oportunizar aos familiares a reflexão sobre suas interações comunicativas - o que possibilita se colocarem, historicamente, num processo de mudança, de outros movimentos e transforma-ações.

Esta primeira etapa possibilitou caracterizar as interações comunicativas entre familiares ouvintes e sujeitos surdos sendo possível identificar a presença da Libras, do Português Oral, do bimodalismo, de gestos e mímicas na comunicação cotidiana das famílias. No entanto, considerando toda a amostra coletada de cada família, a forma de comunicação mais frequentemente observada em suas interações (em todas as seis familias) foi a comunicação bimodal, caracterizada por enunciados nas duas línguas (oral e de sinais) simultaneamente, sendo os sinais usados na ordem gramatical da língua oral e, em outros momentos, o uso predominante da oralidade com a realização de alguns sinais como apoio para a língua oral.

Esta característica de comunicação corrobora com os dados presentes na literatura que demonstram que as famílias se comunicam mais pela oralidade com o sujeito surdo, 
http://dx.doi.org/10.5902/1984686X48563

ou então, realizam combinação entre fala oral e sinais. (GÓES, 1999; OLIVEIRA et al., 2004; KAWABATA et al., 2009; CARVALHO; SANTOS, 2016); comunicação de familiares ouvintes de sujeitos surdos tende a se configurar a gestos representativos, simplificação de conteúdos ou ainda a uma mescla de Língua Portuguesa, gestos e mímicas (GUARINELO et al., 2013).

A questão do bimodalismo, muitas vezes, surge da sensação das pessoas ouvintes de que suas ideias são mais bem transmitidas, quando elas se escutam e, assim, a sinalização acompanha a sua fala oral (MOURA, 2013). Esta situação é bastante comum a uma família que está habituada a uma modalidade de comunicação oral. A surdez carrega uma diferença nem sempre perceptível de imediato, dessa forma, o surdo é "[...] esquecido não de forma proposital, mas circunstancialmente [...]" (SOUZA, 2018, p. 67).

Nota-se que a comunicação desta forma tornou-se habitual entre as famílias, especialmente com os filhos surdos que são oralizados, pois para o familiar ouvinte é uma situação mais confortável enunciar na sua primeira língua (portuguesa oral) e ele percebe que esta maneira muitas vezes satisfaz as necessidades comunicativas.

Também outra característica identificada na comunicação dos familiares ouvintes foi o uso de gestos, mimícas e/ou sinais caseiros. As famílias demonstram reconhecer que o uso de gestos e mímicas é um recurso que as socorrem na falta da língua e, também nos dizem, que apesar da dificuldade da Língua de Sinais, na maioria das vezes, elas não deixam de tentar comunicar, para não deixar o filho à margem, excluído do contexto comunicativo, como apontado no estudo de Souza (2018), ao analisar as narrativas de sujeitos surdos que relatavam se sentirem privados do conteúdo dos diálogos em família.

Lacerda e Nascimento (2016) discutiram que a necessidade de comunicação entre a criança surda e os membros da família e a impossibilidade de acesso à língua oral pela criança, em geral, resulta na criação de sinais caseiros, que permitem uma mínima relação comunicativa, de fazer-se entender. Apontam, todavia, que os gestos e mímicas são uma possibilidade de recurso comunicativo que permite expressar elementos do cotidiano, mas que podem dificultar a realização de conversas elaboradas, fazer argumentações, concordar e discordar, enfim, estabelecer um real processo dialógico. Além disso, os gestos e mímicas podem não ser compreendidos por outras pessoas fora do núcleo familiar.

Lacerda e Lodi (2006) também trouxeram reflexões sobre os pais ouvintes que se empenham no aprendizado da Libras, mas que costumam apresentar pouca fluência na língua. Isto culmina na dificuldade do uso de estratégias visuais, uso restrito de vocabulário 
http://dx.doi.org/10.5902/1984686X48563

e na incompletude de enunciados em Língua de Sinais. Desta forma, essa condição pode levar os familiares a recorrerem aos gestos, mímicas e combinações de sinais para garantir a funcionalidade na comunicação.

Há reflexões acerca dos gestos que estão presentes na linguagem, tanto na sua modalidade oral, como na Língua de Sinais, podendo colaborar inclusive para sua aquisição, considerando a inter-relação entre língua e gesto, uma relação de "[...] interdeterminação - um continuum simbólico [...]" (SANTANA et al. 2008, p. 30, grifos nossos). As autoras ainda concluíram que na ausência de uma língua minimamente referenciada os gestos ocupam um lugar relevante, podendo oferecer ao surdo o papel de interlocutor no diálogo e possibilitando que ele atue no mundo simbolicamente. Todavia, isto não anula ou torna menor o papel fundante que a língua tem para o desenvolvimento, como nos apresenta Vigotski (2007) em sua abordagem histórico-cultural.

A tentativa de analisar o motivo pelo qual a maioria das famílias não utiliza essencialmente a Língua de Sinais perpassa pelo entendimento do processo sóciohistórico (VIGOTSKI, 2007) em que a Libras surge em suas vidas, a sua relação com a língua e representação da mesma (GUARINELO et al., 2013). Neste sentido, como apontou Silva (2007), ao propor às famílias ouvintes o aprendizado e uso da Libras com seus filhos surdos, é necessário conhecer a dimensão do que é aprender uma língua estrangeira, as condições familiares em que o diagnóstico foi divulgado e o funcionamento daquele grupo familiar. Quando tratamos de familiares e seus aspectos linguísticos, adentramos em um complexo de relações familiar ouvinte - língua - familiar surdo.

Considerando este contexto propusemos nas discussões durante o assessoramento, que os familiares se debruçarem sobre essas questões, compreendendo que elas são fundantes no processo de tentativa de transformação da relação que as famílias têm com a língua e com seus filhos. Desta forma, as seguintes perguntas constituíram o pano de fundo para o debate: 1) Libras: qual o seu lugar entre nós?; 2) Por que optaram pela Educação Bilíngue?; 3) Por que escolhi a Libras? A escolhi para quem?; 4) Libras é importante? Para quê? Para quem? Em que momento?; e, 5) Libras: como apoio ou como língua?

O discurso dos familiares revela que a decisão de matricular o sujeito surdo numa escola que assume a abordagem bilíngue partiu de uma experiência educacional anterior não exitosa e da percepção das dificuldades de aprendizagem atreladas a esta experiência. Vislumbravam, então, uma oportunidade de buscar algo melhor para seus filhos. No 
http://dx.doi.org/10.5902/1984686X48563

entanto, não parecia, a priori, haver uma dimensão dos familiares sobre a abordagem educacional bilíngue, que prevê a aquisição de uma língua pela criança, a LS; além do que, seria necessário que esta fosse compartilhada pela família. Este foi um dado também encontrado no estudo de Silva et al. (2007): a escolha pela LS normalmente está atrelada à opção por uma escola de educação bilíngue. No início, as famílias questionam sobre o uso desta língua, demonstram preocupação, ansiedade em relação à aprendizagem da fala e à integração do filho em uma sociedade ouvinte, porém, conforme vão recebendo informações a respeito da língua e do bilinguismo começam a acreditar na LS, principalmente por notarem os progressos educacionais dos filhos.

No que se refere ao papel que a LS tem para o sujeito surdo e o lugar que ela ocupa na relação familiar, os relatos, num primeiro momento, oscilaram entre a compreensão da LS como uma língua e como um apoio. No entanto, a condução da reflexão em grupo, durante a etapa 2, revelou que o seu reconhecimento está para além de um apoio, uma ferramenta, mas seu valor é crescente e tem ocupado um lugar de importância nas relações do familiar ouvinte com o filho surdo, bem como, existe um respeito pela LS como a língua do sujeito surdo (mesmo não assumindo-a efetivamente como sua língua de interlocução), além do reconhecimento da sua importância para o desenvolvimento.

Vigotski (2007) descreveu sobre a relação entre linguagem e pensamento, afirmando que a construção de um conceito abstrato não se consolida sem a palavra, pois ela é o signo mediador. Pela experiência sociocultural e pela linguagem é que o pensamento se desenvolve. Nessa perspectiva, Smolka e Góes (2008) discorreram sobre a apropriação do conhecimento que está fundada numa relação interindividual, mediada por signos. Sendo assim, a internalização das funções mentais superiores concretiza-se a partir das experiências proporcionadas pela cultura na qual aquele sujeito está imerso, possibilitando que ele singularize, diferenciando-se do outro, mas também constituído por sua relação com o outro.

As famílias demonstram, a seu modo, terem notícias deste complexo processo, referindo a importância da LS para a criança aprender, se desenvolver, pensar e opinar, para ter autonomia. Reconhecem ainda que a escola colabora no entendimento dessas questões. Tal aspecto foi ratificado pela pesquisadora (numa linguagem acessível às famílias), mostrando que este desenvolvimento vai além do aprendizado da escola, mas inclui funções psicológicas superiores como: memória, atenção, imaginação, pensamento e linguagem, aspectos psicoafetivos e relações sociais. A tentativa foi também delas se 
http://dx.doi.org/10.5902/1984686X48563

perceberem enquanto este outro, que realiza a mediação na construção de conhecimento e no desenvolvimento da criança, essencialmente quando existe relação interpessoal mediada por uma língua (NASCIMENTO, 2014; PINO,2005).

Este movimento não é simples, como nos aponta Revuz (1998), é um deslocamento contínuo, um sair de si, um tornar-se outro. Tal processo é perturbador e modifica aquilo que estava inscrito em nós com as palavras da nossa primeira língua. A autora também destaca o olhar para dimensão afetiva de se aprender uma língua estrangeira, sendo o desejo motor propulsor do aprendizado. E as questões de desejo, vontade e motivacionais também se fizeram presentes nos relatos das famílias.

De acordo com Gesser (2006), é comum, no contexto de famílias ouvintes e filhos surdos, encontrar posturas diversas de tolerância ou rejeição frente a realidade da surdez e da LS, assim como, sentimentos de culpa, frustração e estresse. Estes aspectos surgem nos discursos dos familiares e diante disso, a pesquisadora valoriza a atitude das famílias de humildade e maturidade em reconhecer esses aspectos, apontando que este percurso de autorreflexão gera possibilidade de mudanças concretas para elas, visto toda sua trajetória e as transformações reais nos seus modos de pensar e agir com o sujeito surdo; isto já fez toda a diferença na vida delas e seus filhos. Com o propósito de encorajá-las, impulsionando-as a irem mais além, foi proposto que pensassem sobre suas motivações em aprender a LS, como alavanca neste percurso.

Destaca-se novamente, a mediação do outro, como possibilidade atuante de reflexão e transformação (VIGOTSKI, 2007), além da importância de pensar nos modos de condução de famílias de sujeitos surdos no processo de relação com LS, pois isso interferirá significativamente na motivação/participação dos mesmos, na aceitação da surdez e da própria Língua de Sinais (CAPORALI, 2005)

A língua envolve comunicação, cuidado, segurança, crescimento, proximidade e vínculo. Ao ressignificar sua relação com a língua, as famílias têm oportunidade também de ressignificar sua relação com o filho. Neste sentido, o reconhecimento das famílias sobre o papel da LS como fonte de transformações em suas histórias também está marcado como fator motivacional para vencerem as fragilidades e perseverarem no aprendizado da Libras.

A questão motivacional perpassou também pelo incentivo da pesquisadora para que elas percebessem que são capazes de aprender LS e ser falantes fluentes desta língua. Essa demanda surgiu a partir da apresentação de vídeo em que mães se comunicavam em Libras com seus filhos surdos em situações práticas do cotidiano, simples e complexas, 
http://dx.doi.org/10.5902/1984686X48563

como por exemplo a filha surda dialogando com a mãe sobre um episódio acontecido na escola.

AVÓ Ferraz: Mas a mãe também é surda?

PESQUISADORA: Por que a senhora está me perguntando isso?

AVÓ Ferraz: Porque ela se comunica muito bem em Libras.(Excerto da etapa 2, CAPPELLINI, 2019)

Esse discurso pode revelar uma percepção de que a pessoa ouvinte não se expressa bem em Libras ou, inclusive, que as famílias ouvintes não acreditam que possam ter fluência na língua tanto quanto as pessoas surdas.

Com o mesmo propósito motivacional e de acolhimento, outra estratégia foi utilizada: um vídeo com depoimentos de estrangeiros que vieram para o Brasil, relatando suas dificuldades de adaptação, sendo uma delas a questão da língua. Foi perguntado às famílias se elas identificaram-se com aquela situação de alguma forma.

MÃE Oliva: Sim, pela falta de comunicação.

MÃE Aquiles: Muito, por causa da dificuldade de ser entendido, a diferença de culturas.

AVÓ Ferraz: Acontece com a gente, a falta da língua, a gente fica perdido. (Excerto da etapa 2, CAPPELLINI, 2019)

As participantes referiram identificarem-se muito com os personagens do vídeo pela falta de comunicação, dificuldade de ser entendido e a diferença de língua e cultura. Para além desta reflexão, este material foi eleito como estratégia para expor o quanto é compreensível o contexto complexo em que elas vivem: a surdez do filho que impõe uma língua a ser aprendida para que elas consigam se comunicar e ele possa se desenvolver. Trata-se da sensação de um estrangeirismo no seio familiar (SILVA, 2007) e a tentativa de acomodar as diferenças linguísticas e culturais, como nos retratou Revuz (1998) e Souza (2018). Apesar de não ser um processo simples, torna-se possível existir e aprimorá-lo, haja vista a aceitação delas em participar desta pesquisa e a disposição para esse processo de assessoramento, reflexão e transformações.

Ainda com relação à língua que lhes é posta e imposta, destacamos o relato de uma das mães após ter assistido ao vídeo sobre estrangeiros no Brasil, seguido de um episódio de interação comunicativa com seu filho, registrado na terceira etapa da pesquisa. 
http://dx.doi.org/10.5902/1984686X48563

MÃE Oliva: Eles têm a língua deles, a gente sendo a maioria quer que eles falem a nossa língua. Mas meu filho também me cobra, eu pergunto um sinal para ele (eu sei que ele sabe) e ele me manda estudar Libras no grupo de famílias. Ele me força a aprender na marra. (Excerto da etapa 2, CAPPELLINI, 2019)

Este episódio descrito a seguir ocorreu na sala da casa, ambos estão sentados lado a lado no sofá, vendo notícias em jornal impresso, disparador trazido pela pesquisadora.

Mãe aponta para uma imagem do jornal, olha para o filho e pergunta)

MÃE: SINAL QUAL (expressão facial de questionamento)

FILHO: (faz gesto indicativo de não com a cabeça)

(Mãe faz um gesto indicativo de esperar e começa a procurar algo no jornal, correndo o dedo indicador sobre o escrito que está ao lado da imagem. $O$ filho acompanha com o olhar e a mãe faz novamente gesto indicativo de esperar. A mãe continua a procurar e faz por duas vezes gestos com a mão e a cabeça demonstrando frustração por não está encontrando o que deseja.)

(O filho retira o jornal da mão dela, sorri para ela, faz um afago e continua sorrindo)

MÃE: RISADA PORQUE?

FILHO: EU AMAR VOCE

(os dois se abraçam)

(Excerto da etapa 2, CAPPELLINI, 2019)

Este episódio demonstra que a mãe insiste em procurar algo no jornal que possa explicar para o filho aquilo que viram na imagem. Ela exige de si, buscando formas de transmitir a informação para seu filho surdo. O esforço e angústia da mãe afetam o filho, por isso, talvez, ele insista para que ela aprenda Libras mas, ao mesmo tempo, ele assume uma postura empática, reconhecendo que não é fácil para a sua mãe este desafio de ser falante da Libras.

Souza (2018) discutiu a língua e seus vínculos a partir de narrativas de surdos que apresentavam duras marcas pela falta da língua no contexto familiar: a comunicação precária, a solidão, o distanciamento dos familiares, a sensação de estrangeirismo. Neste episódio, está presente uma atitude do filho, de amor e compreensão, em relação à mãe. A falta da língua é ressignificada: de distância para proximidade, de cobranças para compreensões, de forma que estreita os laços e mobiliza ambos os sujeitos a superar as fronteiras e criar pontes.

Queremos destacar aqui, por fim, mais um relato desta mesma mãe durante um dos encontros do assessoramento: 
http://dx.doi.org/10.5902/1984686X48563

MÃE Oliva: Vocês não sabem, mas meu marido recebeu uma proposta de emprego muito boa, subir de cargo, ganhar muito mais, só que era em outra cidade. Ahhh. ele não aceitou não, porque lá não tem escola certa pro J. Ele ficou angustiado sabe, mas ele disse: "não, eu preciso priorizar meu filho, minha família em primeiro lugar". (Excerto da etapa 2, CAPPELLINI, 2019)

Este relato nos revela que, mesmo em meio às incertezas, à acomodação e angústias, a Libras já tem raízes nas decisões das famílias. Algumas mobilizações ainda the são desafiantes: como ser assíduo no curso de Libras da escola, priorizar mais a Libras em casa, mas outras não, como abrir mão de excelente proposta de emprego em favor da educação bilíngue do filho surdo. São limites e avanços, idas e vindas, é o possível até este momento do que foi construído da relação com o filho, a surdez, a Libras, e com um advir promissor, pois estas famílias continuam em processo de transformações.

Aranha (1993) apontou que o curso de uma interação é afetado pelas interações passadas e como os sujeitos se dispõem para as relações futuras. O desenho que tem se configurado das interações comunicativas destas famílias com seus membros surdos sofre influências de um percurso histórico, dialético, atravessado por elas e não concluído. Elas continuam em movimento, imersas, (e o aceite em participar da proposta desta pesquisa é uma prova disto) permitindo-se a outras e novas disposições em relação ao filho, neto, irmão e à Libras. Algumas famílias inclusive, externalizaram essa disposição em buscar mais oportunidades como essa oferecida pela pesquisa.

Ao analisar contribuições do processo de reflexão junto aos familiares ouvintes de sujeitos surdos para suas interações comunicativas, notificamos que houve melhorias em todas as famílias e o uso da escala favoreceu visualizar de modo mais objetivo esses dados. Neste sentido, Domeniconi e Gràcia (2018) ratificaram o potencial que o processo de intervenção com as famílias tem para melhorias nas interações comunicativas comcrianças.

Duas famílias em específico, Oliva e Aquiles, apresentaram uma melhora expansiva no modo de comunicar, pois na etapa três, suas interações foram essencialmente em Libras. Em outras duas famílias, Perez e Sande, havia mais um membro da família presente nos contextos comunicativos e referidos como familiares que estão se aproximando mais do sujeito surdo e querendo aprender Libras, considerando que na primeira etapa todos os familiares ouvintes relataram que apenas ele estava efetivamente estudando Libras. Vale ressaltar que para os itens da escala que não foi observado melhoras, se mantiveram no mesmo nível quando comparadas as etapas 1 e 3. 
http://dx.doi.org/10.5902/1984686X48563

\section{Considerações finais}

Este trabalho teve como principal objetivo analisar aspectos de um processo de reflexão de familiares ouvintes de sujeitos surdos acerca de suas interações comunicativas em ambiente doméstico, tendo como ponto de partida a investigação dessas interações. Foi possível notar melhorias em todas as famílias, como: interações comunicativas estruturadas mais em Libras do que em Português oral e a presença de outros membros da família se envolvendo no aprendizado desta língua.

As melhorias não foram uniformes, pois pressupõem um processo histórico-cultural e dialético (VIGOTSKI, 2007), que é único para cada família. Este processo vivido pelos familiares, de movimento, com possibilidades de transformações, não se finda aqui com a conclusão desta pesquisa, mas continua em curso, pois é no plano das interações, das relações cotidianas que o movimento também se encontra e as transformações continuam sendo possíveis.

Conduzir as famílias num processo de reflexões sobre suas interações comunicativas durante o assessoramento, permitiu-nos levantar indícios dos motivos pelos quais a comunicação se concretiza da forma observada. Sendo assim, percebemos o quanto foi peculiar discutir o lugar que a Libras ocupa no seio familiar, na relação com o membro surdo e suas representações, oportunizando ressignificações no pensar e atuar diante da Libras, do membro surdo e de sua diferença - processo apontado pela literatura como fundamental de se olhar e trabalhar (GÓES, 1999; SILVA et al., 2007; KELMAN et al.,2011)

Os encontros de assessoramento também nos possibilitaram a compreensão (e não a constatação ou julgamento, apenas) daquilo que é possível vivenciar por essas famílias em termos de interações linguísticas no cotidiano, considerando suas relações e aspectos sócio-históricos. Reconhecemos que o questionamento dos motivos que levam as famílias a não se comunicarem essencialmente em Libras (mesmo estando envolvidas no seu aprendizado), poderia suscitar um movimento de culpabilização das mesmas; desta forma, optamos por enfatizar as possibilidades dessa comunicação e as formas de aprimorá-la. Apesar de optarmos por não adensar tal questão com as famílias, é uma indagação que ainda permanece. Este trabalho e também os estudos aqui levantados suscitam algumas hipóteses: a relação da família com a surdez, a falta de aceitação da Libras por parte de outros familiares e /ou profissionais que atendem o sujeito surdo, os desafios implicados no aprendizado de uma segunda língua, e ainda, os aspectos psicoafetivos, relacionais e motivacionais de cada familiar. Também é relevante questionar o modo como as famílias 
http://dx.doi.org/10.5902/1984686X48563

estão aprendendo a Libras, lançando o olhar para a estrutura dos cursos oferecidos e os profissionais envolvidos, dando destaque aqui para professores/instrutores surdos e psicólogos.

Esses aspectos trazem limites e possibilidades que circundam as tentativas das famílias em se envolver com a Libras. Isso nos mostra que não podemos afirmar que se trata apenas de uma atitude de descaso, negligência ou falta de interesse pela Libras por parte das famílias ouvintes.

A melhoria das interações comunicativas, após a etapa do assessoramento, nos revela que famílias ouvintes de sujeitos surdos podem e devem ser auxiliadas e suportadas2 no processo de envolvimento da Libras, no entanto, as práticas com famílias ouvintes de sujeitos surdos, especialmente no que tange o ensino- aprendizado da Libras, são escassas e desafiadoras. Tal suporte deve e pode ser assumido pelas instituições de Educação Bilíngue para surdos, provendo práticas positivas de parceria, entre família e escola, enquanto corresponsáveis pela constituição de sujeitos bilíngues. Estar com as famílias é importante em processos contínuos de ensino da Libras, assim como, de escuta e acolhimento.

\section{Referências}

ARANHA, Maria Salete Fábio. A interação social e o desenvolvimento humano. Temas em Psicologia, Ribeirão Preto, v. 1, n. 3, p. 19-28, 1993.

CAPPELLINI, Michele Toso. Familiares ouvintes de sujeitos surdos: reflexões sobre suas interações comunicativas. 2019. 115f. Dissertação (Mestrado em Educação Especial) programa de Pós graduação em Educação Especial, Universidade federal de São Carlos, São Carlos, 2019.

CAPORALI, Sueli Aparecida; LACERDA, Cristina Broglia Feitosa de; MARQUES, Penelope Leme. Ensino de língua de sinais a familiares de surdos: enfocando a aprendizagem. Pró-Fono R. Atual. Cient., Barueri, v. 17, n. 1, p. 89-98, 2005.

CARVALHO, Denise Moura; SANTOS, Layane Rodrigues de Lima. Pais ouvintes, filho surdo: causas e consequências na aquisição da língua de sinais como primeira língua. Revista Sinalizar, Goiás, v.1, n.2, p. 190-203, 2016.

CONCEIÇÃO, Bianca Salles; MARTINS, Vanessa Regina de Oliveira. Discursos de pais de crianças surdas: Educação Infantil e a presença da Libras. Educação, v. 44, p. 1-24, 2019. Disponível em: https://periodicos.ufsm.br/reveducacao/article/view/38319/html. Acesso em: out.2020. 
DOMENICONI, Camila; GRÀCIA, Marta; BENITEZ, Priscila; VESSONI, Julia. Adaptação da escala de avaliação do Ensino de linguagem oral em contexto escolar (EVALOE) para seu uso em contexto familiar (EVALOF). Revista de Psicologia da criança e do adolescente, v. 8, p. 65-80, 2017.

DOMENICONI, Camila; GRÀCIA, Marta. Efectos de una intervención siguiendo el modelo enfocado en la familia para promover avances en el desarrollo del lenguaje de los niños. Revista de Investigación en Logopedia, v.8, n. 2, p. 165 -181, 2018.

GARCEZ, Andrea; DUARTE, Rosalia; EISENBERG, Zena. Produção e análise de vídeogravações em pesquisas qualitativas. Educação e Pesquisa, São Paulo, v. 37, n.2, p. 249-262, 2011.

GESSER, Audrei. Um olho no professor surdo e outro na caneta: ouvintes aprendendo a língua brasileira de sinais.2006. 215f. Tese (Doutorado em Linguística Aplicada) Programa de Pós-Graduação em Linguística Aplicada, Universidade Estadual de Campinas, Campinas, 2006.

GOES, Maria Cecília Rafael de. Subjetividade, linguagem e inserção social: examinando processos de sujeitos surdos. Revista de Ciências Humanas, Florianópolis, Edição Especial Temática, p.43-59, 1999.

GUARINELLO, Ana Cristina; LACERDA, Cristina Broglia Feitosa de. O grupo de familiares de surdos como espaço de reflexão e possibilidades de mudança. In: SANTANA, Ana Paula; BERBERIAN, Ana Paula; GUARINELLO, Ana Cristina; MASSI, Giselle (org.). Abordagens grupais em Fonoaudiologia: contextos e aplicações. São Paulo: Plexus, 2007. cap. 5, p.105-120.

GUARINELLO, Ana Cristina; CLAUDIO, Débora Pereira; FESTA, Priscila Soares Vidal; PACIORNIK, Roseli. Reflexões sobre as interações linguísticas entre familiares ouvintes filhos surdos. Ciência e Cultura, Curitiba, n. 46, p. 151-168, 2013.

KAWABATA, Silvia Regina; TANAKA, Eliza Dieko Oshiro. Comunicação entre pais ouvintes e filhos surdos. In: V Congresso Brasileiro Multidisciplinar de Educação Especial, 2009, Londrina. Anais... Londrina: p. 985 -994. Disponível em: http:// www.uel.br/eventos/congressomultidisciplinar/pages/arquivos/anais/2009/119.pdf. Acesso em jul, 2018.

KELMAN, Celeste Azulay; SILVA, Daniele Nunes Henrique; AMORIM, Ana Cecília Ferreira de; MONTEIRO, Rosa Maria Godinho; AZEVEDO, Daisy Cristina. Surdez e família: facetas das relações parentais no cotidiano comunicativo bilíngue. Linhas Críticas, Brasília, v. 17, n. 33, p. 349-365, 2011.

LACERDA, Cristina Broglia Feitosa de. Os processos dialógicos entre aluno surdo e educador ouvinte: examinando a construção de conhecimentos. 1996. 153f. Tese (Doutorado em Educação) - Faculdade de Educação, Universidade Estadual de Campinas, Campinas, 1996. 
LACERDA, Cristina Broglia Feitosa de; LODI, Ana Claudia Balieiro. O desenvolvimento do Narrar em Crianças Surdas: o contexto de grupo e a importância da língua de sinais. Temas sobre Desenvolvimento, São Paulo, v. 15, n.85-56, p. 45-53, 2006.

LACERDA, Cristina Broglia Feitosa de; LODI, Ana Claudia Balieiro. A inclusão escolar de alunos surdos: princípios, breve histórico e perspectivas. In: LACERDA, Cristina Broglia Feitosa de; LODI, Ana Claudia Balieiro. Uma escola, duas línguas: letramento em língua portuguesa e língua de sinais nas etapas iniciais de escolarização. Porto Alegre:

Mediação, 2010. cap. 1, p. 11-32.

LACERDA, Cristina Broglia Feitosa de; SANTOS, Lara Ferreira; MARTINS, Vanessa Regina de Oliveira. Escola e Diferença: caminhos para educação bilíngue de surdos. São Carlos: Edufscar, 2016. 241 p.

LACERDA, Cristina Broglia Feitosa de; NASCIMENTO, Lilian Cristine Ribeiro. Aquisição de Linguagem: Refletindo sobre a Criança Surda e a Língua de Sinais. In: LAMÔNICA, Dionísia Aparecida Cusin; BRITTO, Denise Brandão de Oliveira e. Tratado de linguagem: perspectivas contemporâneas. Ribeirão Preto: Booktoy, 2017, cap.6, p. 5-10.

LLOBERA, Fatima Vega; GRÀCIA, Marta; BENITEZ, Priscila V. Avaliação do ensino da linguagem oral em sala de aula: utilizando a ferramenta EVALOE no Brasil. Revista Ibero-Americana de Estudos em Educação, v. 12, n. 2, p. 1085-1103, 2017. Disponível em: https://periodicos.fclar.unesp.br/iberoamericana/article/view/9125/6584. Acesso em: 04 ago. 2018.

MOURA, Maria Cecília. Surdez e linguagem. In: LACERDA, Cristina Broglia Feitosa de; SANTOS, Lara Ferreira. Tenho um aluno surdo e agora? - Introdução à LIBRAS e educação de surdos. São Carlos: EdUFSCar, 2013. p. 13-26.

NASCIMENTO, Rubem de Oliveira. Um estudo da mediação na teoria de Lev Vigotski e suas implicações na educação. 2014. 406f. Tese (Doutorado em Educação) - Programa de Pós-graduação em Educação, Universidade Federal de Uberlândia, Uberlândia, 2014.

OLIVEIRA, Raquel Gusmão Oliveira; SIMIONATO, Marlene Aparecida Wischral; NEGRELLI, Maria Elizabeth Dumont; MARCON, Sonia Silva. A experiência de famílias no convívio com a criança surda. Acta Scientiarum Health Sciences, Maringá, v. 26, n. 1, p. 183-191, 2004.

PINO, Angel. As marcas do humano: às origens da constituição cultural da criança na perspectiva de Lev S. Vigotski. São Paulo: Cortez, 2005. 303p.

PINTO, Milena Maria; SANTOS, Lara Ferreira dos. A contribuição das brincadeiras para o aprendizado de Libras por crianças surdas. The Especialist, [S.I.], v. 41, n. 1, maio 2020. Disponível em: http://ken.pucsp.br/esp/article/view/42412. Acesso em: 08 set. 2020.

REVUZ, Christine. A língua estrangeira entre o desejo de um outro lugar e o risco do exílio. In SIGNORINI, Inês. Língua(gem) e identidade. Campinas: Mercado de Letras/FAPESP/FAEP/UNICAMP, 1998, cap. 2, p. 213-230. 
RODRIGUERO, Celma Regina Borghi; YAEGASHI, Solange Franci Raimundo. A família e o filho surdo: uma investigação acerca do desenvolvimento psicológico da criança segundo a abordagem histórico cultural. 1.ed. Curitiba: CRV, 2013.112p.

SANTANA, Ana Paula; GUARINELLO, Ana Cristina; BERBERIAN, Ana Paula; MASSI, Giselle. O estatuto simbólico dos gestos no contexto da surdez. Psicologia em Estudo, Maringá, v. 13, n. 2, p. 297-306, 2008.

SANTOS, Lara Ferreira. O fazer do intérprete educacional: práticas, estratégias e criações. 2014. 200f. Tese (Doutorado em Educação Especial) - Programa de pósgraduação em Educação Especial, Universidade Federal de São Carlos, São Carlos, 2014.

SCHEMBERG, Simone; GUARINELLO, Ana Cristina; MASSI, Giselle. O ponto de vista de pais e professores a respeito das interações linguísticas de crianças surdas. Revista Brasileira de Educação Especial, Marília, v.18, n.1, p. 17-32, 2012.

SILVA, Gláucia Faria. Reflexões psicanalíticas sobre a língua, o estrangeiro e a intimidade em casos de surdez profunda. Psicol. Am. Lat., n. 9, 2007. Disponível em: http://pepsic.bvsalud.org/scielo.php?script=sci_arttext\&pid=S1870350X2007000100011\&l $\mathrm{ng}=\mathrm{pt \& nrm}=$ iso. Acesso em jul.2018.

SILVA, Angélica Bronzatto de Paiva e; PEREIRA, Cristina da Cunha; ZANOLLI, Maria de Lurdes. Mães ouvintes com filhos surdos: Concepção de surdez e escolha da modalidade de linguagem. Psicologia: Teoria e Pesquisa, Brasília, v. 23, n. 3, p. 279 -286, 2007.

SOUZA, Geilda Fonseca de. Relações familiares entre surdos e ouvintes: análise de narrativas biográficas. 2018. 153f. Dissertação (Mestrado em Educação) - Programa de Pós-graduação em Educação, Universidade Estadual de Campinas, Campinas, 2018.

SMOLKA, Ana Luiza Bustamante; GÓES, Maria Cecília Rafael de (orgs.). A linguagem e o outro no espaço escolar: Vygotsky e a construção do conhecimento. 12ed. Campinas: Papirus, 2008.

TURETTA, Beatriz Aparecida dos Reis; LACERDA, Cristina Broglia Feitosa de. Representação simbólica por crianças surdas na Educação Infantil. Horizontes, v. 36, n. 3, p. 24 - 35, set./dez. 2018. Disponível em: https://revistahorizontes.usf.edu.br/horizontes/article/view/718/312. Acesso em 15 ago 2020.

\section{Notas}

1 A escala completa está disponível no trabalho CAPPELLINI, 2019: https://repositorio.ufscar.br/handle/ufscar/11617. Acesso em out, 2020. ${ }^{2}$ A primeira autora deste estudo foi responsável pelo desenvolvimento da pesquisa, sob orientação da
segunda autora.

${ }^{3}$ Ao pesquisar o significado do verbo suportar em diferentes dicionários da Língua Portuguesa, destacamos esse sentido: ser capaz de segurar ou carregar. A família necessita ser acolhida por profissionais dispostos a não questionar, mas capazes de segurar em suas mãos, seja para lhe ensinar um sinal, seja para, dizer-lhes Você não está sozinha. 
http://dx.doi.org/10.5902/1984686X48563

\section{Correspondência}

Michele Toso Cappellini - Rua Dr. Pedro Raimundo, 21, Vila Carmem, São Carlos, São Paulo - Brasil.

CEP: $13575-332$

(c) (i) (9)

This work is licensed under a Creative Commons Attribution-NonCommercial 4.0 International (CC BY-NC 4.0) 